\title{
Looming Threats to Society Journals
}

\author{
Kimberly Douglas and Dana L. Roth \\ California Institute of Technology
}

Now is not the time for members of professional scientific societies to be complacent or unengaged. The American Chemical Society Publications Division, as well as other learned society publishers, such as the Royal Society of Chemistry, may be overly confident that the obvious high quality of their journals will ensure their position against commercial competitors.

In addition, when they resist open-access efforts, society publishers appear to be more aligned strategically with commercial publishers' short-term perspective than with the research community's need to easily access all relevant content over the long term.

Societies need to adhere closely to their members' needs, even if that means a break with their for-profit counterparts. University faculty and administrators need to engage with librarians to ensure that the best decisions are being made for the long term.

The general high quality of society publications is taken for granted by all professionals, including the science and engineering librarians who are largely responsible for selecting and purchasing them for their institutional libraries. But research libraries face unprecedented and unsustainable demands on their budgets across all disciplines.

Unfortunately, an increasingly large component of this demand comes as a result of the commercial publishers leveraging high prices on individual title subscriptions to force librarians to purchase discounted publisher-selected collections_-or bundles_of their journals at fixed prices. Librarians cannot adequately consider the cost-effectiveness or quality of each individual title, let alone the downstream effect of compounded percent increases over time.

In bundled licenses, lower quality and often irrelevant titles are routinely included along with those of higher quality. The multiyear contracts for journal titles bundled in these licenses tie up university funds that might otherwise go toward newer, innovative, smaller, yet valuable titles from other publishers, especially nonprofit publishers, and toward expansion of society publishing volume. For this reason, the university's ability to sustain access to the most valuable scholarship is in danger of serious erosion over the long haul.

It is time for library administrators to enforce and for university faculty and administrators to support a journal quality and cost-effectiveness metric. Purchase decisions need to be based on a computationally rigorous evaluative approach that encourages high-quality papers and can be tailored to each community's cost-effectiveness metric.

If librarians cannot say no to bundles or to exorbitant prices, all prices will progressively increase. Rate hikes will be based on the inflationary expenditures of the past and more mixing of content for high volume, not better quality (1-3). Poor content needs to be driven out or acquired at a price commensurate to its value.

The library's book and journal purchases reflect the university’s allocation to making the highquality information easily and seamlessly available to students and faculty for their education and research. These purchases constitute a commons, a shared resource created from community assets. A sustained quality-based commons requires comparative analysis of purchases for price, quality, and costeffectiveness.

For journals, comparative metrics such as price per page, price per article, price per character, and price per local use can be calculated and used to compare publishers and titles.

ISI's Impact Factor (IF) is a widely used, though not perfect, indicator of a journal's quality (4). It is also not immune to manipulation (5), although it is the most easily available.

The IF measures how many times an "average article" published by a given journal in the two preceding years has been cited in a particular year. Though this measure tends to lose pertinence when 
applied across the full spectrum of journals, within a defined field and for similarly targeted journals, it strongly correlates with quality. It is also reproducible and will be used for that reason in this article.

The information science community is working on other measures that provide more probing insight to scholarship. Advances will be forthcoming. After all, the story of quality is fundamentally about the papers and their authors and less about journal titles. Nevertheless, libraries' resources are expended according to journal title and publisher.

In 1988, Henry H. Barschall (6) introduced a technique to calculate cost-effectiveness, a ratio of price per 1,000 characters to IF (p/c/IF). Barschall's method has been extended by Roth (7) to price per page (p/p/IF). For example, Biomacromolecules has a 2004 price/page of $\$ 0.39$ and a p/p/IF of 0.12. Biopolymers has a 2004 price/page of $\$ 2.94$ and a p/p/IF of 1.03. Thus Biomacromolecules is less expensive by a factor of 7.6 and is over 8.8 times more cost effective than Wiley's comparative publication.

Another quantitative measure is that of a publisher's scholarly impact in a discipline. This measurement can be done by identifying a set of journal titles for a discipline, then calculating the number of papers published in each title in a year, and multiplying that figure by the quality factor (ISI's IF in this case). The final figure for all the titles is added to obtain a $100 \%$ number, and then the output is grouped by journal publisher to calculate the percentage impact in that discipline by publisher.

Thus, taking the dataset of 125 multidisciplinary chemistry titles and now multiplying each journal's 2004 article count by the appropriate IF, we find that the 12 ACS journals account for $48.44 \%$ of the total scholarly impact in the field. This is an important figure when examining where the library's resources are being spent.

In addition to these results, ACS journals also rank very low in price-per-article comparisons. In 2004 , the price per article of ACS research journals ranged from $\$ 0.80$ to $\$ 3.80$, which compares very favorably with those of Elsevier Academic Press (\$4.36-\$10.26), Elsevier Pergamon Press (\$2.85\$16.42) Springer (\$6.42-\$10.69), Wiley learned society titles (\$3.04-\$5.75), and Wiley commercial titles (\$10.17-\$40.41) (8).

Such pricing spreads between society and commercial publishers are also documented in Bergstrom (9) and the journal pricing database Journal Cost Effectiveness, created by Bergstrom and McAfee (10).

In this age of the Internet, eliminating titles that are not cost-effective for the library commons no longer has the same impact that eliminating a print subscription had in the old days. Given the pay-perview availability of many articles, it is now possible to include the individual reader as an active participant in scholarly publishing economics.

If a given journal is so expensive that it is not cost-effective and is therefore not selected to be part of a library's offerings, the individual readers can purchase needed articles themselves, order them through Interlibrary Loan, or look for adequate substitutes on the Web. Such availability constitutes substitution for library purchases and is an important alternative to constrain commercial publishers' unrelenting demand for cash.

Librarians have begun to include those readers' options in modeling expenditures in the scholarly journal market. University administrators and faculty must consider this in deciding the relative merits of library versus research budget expenditures for access to the literature. When the purchase is in the hands of the individual, demand suddenly becomes very elastic, a dynamic lacking in the library subscription model.

Because of the exploding increase in submissions due to grant and other competition, as well as the entrance of new productive research communities in Asia, high-quality journals published by learned society publishers will require steady increases in subscription prices as they expand to accommodate this growing volume. Professional societies do a better job of combining quality and cost-effective publishing than most commercial publishers do. Since libraries and their institutions struggle with any price increase, it is essential for libraries to do the following:

- Select the highest quality, most cost-effective materials for their collections. 
- Avoid bundle contracts from commercial publishers and instead only select the most relevant, high-quality titles from such vendors (11).

- Gain support from university administrators and faculty for the necessary selection and unbundling actions.

Taking these actions will allow libraries faced with budgetary stasis or even reductions to provide their constituencies with unhindered access to the very best scholarly materials.

\section{REFERENCES}

1. Edlin, A. S.; and D. C. Rubinfeld, “The Bundling of Academic Journals.” Amer. Econ. Rev. 2005, 95, 441.

2. McCabe, M. “Academic Journal Pricing and Market Power: A Portfolio Approach,” www.prism.gatech.edu/ mm284/JournPub.PDF.

3. Bergstrom, C.; and T. C. Bergstrom, "The Costs and Benefits of Library Site Licenses to Academic Journals.” Proc. Nat. Acad. Sci. U.S.A. 2004, 101, 897.

4. “The ISI Impact Factor.” scientific.thomson.com/free/essays/journalcitationreports/impactfactor.

5. Begley, S. "Science Journals Artfully Try To Boost Their Rankings.” Wall Street Journal, June 5, 2006, page B1.

6. Barschall, H. H. “The Cost-Effectiveness of Physics Journals.” Physics Today 1988, 41, 56.

7. Roth, D. L. "Value and Quality Measures for Chemistry Research Journals.” http://resolver.caltech.edu/CaltechLIB:2006.003

8. University of Wisconsin-Madison . Journal Value Project (2004). Board of Regents of the University of Wisconsin System, www.wendt.wisc.edu/projects/jvp/welcome.do.

9. Bergstrom, C., op. cit. p. 867.

10. Journal Cost-Effectiveness database and calculation tool, journalprices.com, developed by R. Preston McAfee and Theodore C. Bergstrom.

11. Frazier, K. “The Librarians' Dilemma: Contemplating the Costs of the 'Big Deal'.” D-Lib Magazine, 2001, 7(3), www.dlib.org//dlib/march01/frazier/03frazier.html.

Published in: Chemical and Engineering News, v. 84(47):82-84, November 20, 2006. Views expressed in this article are those of the authors and not necessarily those of ACS. 